Article

\title{
Models of Disability as Models of First Contact
}

\author{
Sheri Wells-Jensen * and Alyssa Zuber \\ English Department, Bowling Green State University, Toledo, OH 43402, USA; azuber@bgsu.edu \\ * Correspondence: swellsj@bgsu.edu
}

Received: 15 October 2020; Accepted: 10 December 2020; Published: 17 December 2020

check for updates

\begin{abstract}
Because humanity is a young technological species, any extraterrestrials we meet will inevitably be more advanced than we are. The realization that we are no longer dominant in our sphere of influence will inevitably cause spiritual cultural and even economic trauma as we come to terms with the new reality. The question we should endeavor to answer before this happens is: what direction will this trauma take and how can we prepare in advance to minimize harm as we adjust to this? Disability studies offer several models of how one advantaged group understands and interacts with a less advantaged group. These include the medical, social, moral/religious, economic, charity, and limits models, and each lays out a unique way of understanding situations where one group has a strong perceived or real advantage over another. Exploring these models can give us a sense of the possible variation that might occur upon first contact. Such an exploration is relevant both to how ET might perceive us and how we might begin to conceptualize ourselves in that new situation. As with most seemingly theoretical forays into astrobiology, this work has implications for the present as it interrogates how disabled and abled humans interact and negotiate power and how we understand one another.
\end{abstract}

Keywords: religion; outer space; cognition; space exploration; culture; history; science

\section{Introduction}

The scene has been retold countless times. In the summer of 1950, Physics Nobel Laureate Enrico Fermi was having lunch with colleagues. Without warning, he interrupts the conversation and asks: "Where is everybody?" This, no doubt, created some confusion until it was sorted out that he was referring back to a discussion he and colleagues had had earlier that morning about a series of UFO sightings in the news. His argument, and his question, went something like this: if, as has since been made clear, there are countless habitable planets circling countless other stars, and if these planets have had great expanses of time during which they could have brought forth life and later perhaps intelligence, why was the Milky Way not awash in advanced alien civilizations? And why, given that possibility, had we not been contacted?

This question has since become known as the Fermi paradox (Shostak 2018), it has sparked a great deal of scientific and philosophical debate, and its implications have been examined from every imaginable perspective. Bold and marvelous as humankind believes itself to be, the first contact with a truly advanced alien civilization will produce a reaction on a global scale as everyone alive is called to readjust their notion of themselves, humanity, and what the cosmos is like.

It is at least conceivable that, if we do make contact with an intelligent extraterrestrial species, their civilization would also be just finding their way into their own electronic age, but the odds are better that they will be significantly older and more experienced, well into whatever phase of development comes after ours (Davies 1995). They will most likely be far beyond us in every way we can conceive. Still, it may be possible to imagine what advanced technology might be like (Arthur 2011), but it is much more difficult to deduce how cultural or spiritual progress would manifest (Harari 2015). That is, 
we might be able to guess what sorts of things they will have, but we will have a much harder time imagining what kind of people they will be.

More to the point, we will be forced to consider what such people will think of us, and what will happen to us once this connection is made. There have been attempts to think through the impact that contact will have on Earth civilization (Davis 2017; Dick 2018) and on religions in particular (Ambrosino 2016; Weintraub 2014). One of the often-used models used to frame these speculations is that of aboriginal people encountering western explorers. On Earth, these first contact scenarios have historically gone very, very badly for the less-technologically-savvy participant, resulting in everything from profound cultural disruption to genocide (Harari 2015). If what goes around comes around, humanity will be profoundly demoralized, perverted, or inevitably assimilated in the resulting culture (Sturm und Drang), assuming we survive at all.

How else could it go? We would be outmatched at every angle. What we must hope for is a different possibility, one where a dominant culture meets and manages to coexist with a less powerful player. It is inordinately credulous to assume that such an interaction will unfold without some undesirable consequences, but what scenarios could we explore where we, as the less powerful participant, would do at least a little better?

One scenario we have here on Earth that at least partly fits this bill is the ongoing interaction between mainstream culture and disabled people. In every country, disabled people are systematically less wealthy, are less likely to receive adequate health care and jobs, have less freedom of movement, and are subject to more abuse than able peers (World Health Organization 1976). This kind of imbalance of power and unequal access to resources is a classic breeding ground for conflict and does frequently result in violence (Brown 2002; Sherry et al. 2019; Sherry 2010; Wilkin 2019; Evans 2004). Still, despite this wider context, interactions between these groups on the personal level are often loving and mutually beneficial.

Could we apply what we know about disability on Earth to the problem of how to survive, or at least begin to imagine, a first-contact event? Disability studies offer a set of models (sometimes conflicting, sometimes overlapping) of how humanity has come to think about disability (Davis 2017; Retief and Letsosa 2018; Camble and Oliver 1996; Nielsen 2013; Williamson 2019). They are, by and large, a disheartening set of observations on humanity's steady propensity to get things wrong-to repeatedly act out of self-interest and fear rather than love and compassion. Still, they do describe a way in which a dominant culture and a less-powerful culture have managed to coexist (albeit sometimes uneasily) across the centuries. Disabled people and abled people do interact with some degree of ease in some circumstances, but the conflict between these groups (which is generally absorbed by the disabled community and not often recognized by the abled community) is ongoing. With a few caveats, these models can usefully be applied to the first-contact situation.

First, while we chose models that represent the most common approaches to disability, some variants and offshoots are not covered here. We also resisted the temptation to include reflections from outside the discipline of disability studies per se as these are beyond our present scope. This does place a definite western perspective on our work, and as disability studies is a young field, we trust that repeating this analysis in another generation would permit the inclusion of more global perspectives.

Second, for the purposes of exploring the models, we make a set of simplifying assumptions: that there is only one ET civilization, that only one model is active at a time, that this is the only relevant influence on behavior, and that everyone in the ET society shares this approach, that the ETs have concepts similar to God-a higher power, commerce, and charity, where these apply, and that the goal of human-ET interchange would be an ongoing friendly and mutually beneficial interaction. This is quite a bit to assume, but we do this to make it possible to isolate and meaningfully discuss the chosen models.

Finally, we explore these scenarios with the disabled participant playing the role of current humans and the abled participant standing in for the extraterrestrials. By this, we do not intend to deny the fact that there are indeed circumstances when disabled people do wield social and economic 
power. Through the centuries, individual disabled people have held almost every conceivable position in society, including soldier, doctor, explorer, sailor, politician, teacher, religious leader, parent, athlete, business owner, farmer, and criminal. However, such individual success stories are noteworthy because they are unusual, the result of exquisite combinations of perseverance, talent, luck, and opportunities brought about by advancing technology and the intermittent softening of some of the harsher socially imposed limits on the disabled populace.

Note that in this paper we will be using "identity-first" language, rather than "person-first" language. That is, we will say "disabled person" rather than "person with a disability". The choice is not politically or socially neutral. Identity-first language is coherent with the social model of disability (Consult Brown 2011; Vaughan 2009), while person-first language is often required by professional journals in rehabilitation, medicine, and many of the social sciences. As the social model reflects the authors' philosophy, we use identity-first language here, while acknowledging that other disabled people may choose to identify themselves in other ways.

Models of disability and their implications for the first contact.

\section{The Religious/Moral Model: Part 1}

The Lord will smite you with madness and with blindness and with bewilderment of heart. (2 Samuel 4:4)

Perhaps the oldest conceptualization of disability is the religious/moral model in which present disability is a just punishment for past or even ancestral behaviors that violate religious, moral, or social taboos, i.e., sins (Pardeck and Murphy 2005; Henderson and Bryan 2011). There is no way to readily determine which moral rule was broken or even who in the person's family committed the offense, but there is an implicit understanding that "more severe" disabilities (such as full blindness or quadriplegia) must have resulted from something especially prurient. "Afflicted" people (and sometimes their families) may be ostracized by the righteous, upstanding community. They are cast out as not only potentially physically contagious but also spiritually corrupt and worthy of contempt, this judgment occasionally mediated by small, ostentatious doses of pity by people who consider themselves forward-thinking or merciful. On the individual level, this can result in violence (particularly infanticide), but often social and economic isolation suffice, as long as the afflicted remain marginalized.

Since the just punishment of God has already been meted out, there is little the community needs to do beyond keeping a prudent distance and admonishing the afflicted to repent. Optimists might determinedly imagine that this belief system is passé, but thousands of people living with HIV provide clear examples that the idea of "God's wrath" is alive and well in some corners of 21st century Christianity (Olaore and Olaore 2014; Petro 2015). Under these circumstances, there is no chance of obtaining employment, equal education, or free access to society.

If ET were to view humans as "afflicted" in this way, the simplest solution for them would be to avoid contact with Earth in the first place, creating a new and intriguing explanation for the Fermi paradox placing Earth more or less permanently on the "do not visit" list. Extraterrestrials would approach Earth, make the determination that humans are off-limits, and move along. It is, of course, also conceivable that extraterrestrial zealots would decide to do "God's work" by eradicating humankind, as a means of cleansing the galaxy of infidels and heretics. Although this hardly seems worth the bother considering the distances (and presumably the costs) involved, human religious extremism, at least, does not appear to be sensitive to these kinds of economic issues. There are several good reasons, therefore, to hope this is not the way things go.

\section{The Religious/Moral Model: Part 2}

Jesus answered: "Neither hath this man sinned nor his parents: but that the works of God should be made manifest in him". (John 9:3) 
Still holding to the perspective that disability is caused by a supernatural power, the same "affliction" can be explained as a special (if somewhat peculiar) blessing.

Disabled people (and, once again, sometimes their families) are understood to be chosen by God to withstand the disability and thereby gain patience, courage, and (usually) admirable docility through suffering (Niemann 2005). They are inspirational, a rhetorical and sometimes literal point of comparison used to alternately shame and motivate able-bodied people to "do better" (Young 2012). These chosen ones are supposed to draw goodness to themselves and through their suffering manufacture, if not happiness, at least an abiding sense of divine joy. Crucially, they are vehicles through which the power of the almighty may be revealed, but this special status rarely translates into anything remotely like equal access in the secular sphere. As symbols of virtue, endurance, or wisdom, they remain outside the mainstream, ill-suited for ordinary activities.

Once again, some might consider this model of disability to be somewhat antiquated, but the lived experiences of disabled people provide ample evidence that it is alive and well. Encouraged in their charism by advocates of the "prosperity gospel" (such as Wilkinson 2013; Roberts 1966), many people who adhere to this model of disability believe that healings will occur and that disabled people will be the vehicle for God's mercy manifesting on Earth. Rose (2019) provided a description of how members of the public frequently approach disabled strangers and offer to pray (indeed, sometimes insist on praying) for their healing as a manifestation of God's mercy and power. The first author can attest that this is not at all unusual, having herself been confronted many times by determined evangelists on the street, on college campuses, and on public transportation.

If ET conceptualizes humanity as "blessed" in this way, our interactions would be extraordinarily difficult. As channels of potential divine expression, we might gain some access to ET society, but in a severely compromised manner. Many might want to meet a channel of their God's goodness and would likely feel called to protect and even admire such individuals, but they are not expected to be friends or colleagues. It might also be considered unnecessary, or even heretical, to interfere in Earth society even where such interference might bring benefit. This would protect humanity from direct harm caused by ET but might make it difficult for us to secure economic, technological, or cultural gain from such interactions with their advanced civilization. Once again, it seems like this would not work to our advantage.

\section{The Charity Model}

No one would remember the Good Samaritan if he'd only had good intentions-he had money as well. (Thatcher 1981)

A more secular approach to disability sets aside the religious aspect of causation and focuses on a benevolent (sometimes fully humanist) reaction to the perception that disabled people are profoundly unfortunate. If human beings are ethical creatures, it is incumbent on the community to respond benevolently, and the giving of alms and caring for the less fortunate is a secular as well as a religious obligation. The mandate is for a culture of care-for which disabled people are reasonably assumed to be grateful. It is given that the recipients will accept charity; to do otherwise would be churlish if not perverse.

Wrapped up in these perceptions is the unspoken assumption that disabled people cannot, and should not be expected to, arrange for their own material needs (Retief and Letsosa 2018). They are also not expected or permitted to specify what those needs might be; the benefactor is assumed to know what to give, and the recipient is expected to cooperate. In this case, disabled people are not understood as specifically created for the purpose of receiving charity, but charity itself is viewed as a communal good-as long as its object remains reasonably worthy.

If ET operates from a charity model, we might initially find ourselves quite satisfied with the onslaught of resources. We might benefit from a cleaned-up environment, improved medical care, and the end to violence at all levels. Eventually, though, as we progress and perhaps after the initial euphoria fades, we may find ourselves profoundly frustrated by our role as eternal children, never 
perceived as equals. Furthermore, as recipients of galactic charity without the mitigating factor of also being somehow blessed, we could well find ourselves rebuffed, abandoned, or punished if we are perceived as ungrateful or if we are eventually deemed unworthy for some reason.

\section{The Medical Model}

Impairment is defined as any loss or abnormality of a psychological or anatomical structure or function. Disability is defined as any restriction or lack of ability resulting from an impairment to perform an activity in the manner or within the range considered normal for a human being (World Health Organization 1976).

Since early humans began the hunt for medicinal herbs, we have naturally searched for ways to cure diseases and lessen pain (Porter 2004). When progress is made, people are relieved of some of their unnecessary suffering. Classifying disability as just one more kind of illness, doctors have arrayed themselves against disabilities of all kinds. In the medical model, the problem disability is purely physical, and experts with the right kind of knowledge can and should work to cure it (Olkin 1999). Doctors, psychologists, social workers, teachers, therapists, and others become the experts, and the goal is to transform the disabled person into a non-disabled person, for their good and for the good of all society.

Of course, the disabled person is naturally expected to submit to whatever treatment is deemed necessary by the experts (Thomas and Woods 2003). Resisting "necessary" treatments when they are offered is perceived as either peculiar or as evidence of further pathology. Modern objections notwithstanding (Pfeiffer et al. 2003; Wells-Jensen and Wells-Jensen 2019), this is a widely accepted perspective. Based as it is in science and in Western notions of objectivity, this is perhaps the model that feels most natural to most people. This trope is taken up by various science fiction authors who affirm the wisdom of eliminating disability with everything from high-tech prosthetics (cf. the "blind" Star Trek engineer Geordi La Forge who functions as fully sighted) to full-body transplants (cf. the wheelchair user in Avatar, Jake Sully, whose consciousness is transplanted into an alien body).

It is quite possible to imagine that an alien civilization, with a superior understanding of biology or equipped with other means of artificially extending life and modifying bodies, would think it obvious that humans need, and would welcome, various "treatments". We might find some of this very pleasant indeed, as disease, pain, and perhaps even old age are eliminated.

On the other hand, one might imagine dystopian scenarios where humans are forcibly reconstructed as immortal machines or new sensory inputs are added and offending senses removed, as our bodies, senses, and even minds are reconstructed to meet alien standards of ableness. Refusal to participate might cause firm, paternal intervention as noncompliant humans are forcibly transformed "for their own good". After the possibility that the entire Earth would be destroyed as a hotbed of heresy, this is perhaps the most ominous of the explorations so far.

\section{The Economic Model}

Nothing is more important than your health ... except your money. (Ferengi Rules of Acquisition 1993, \#23)

Disability can be viewed as an economic problem to be solved, the key to which is labor. In the economic model, everything hinges on estimations of a person's ability to work and how to construct public policy around the problem of citizens who do not "contribute their share". Opinions that those citizens themselves might hold on the matter are of some interest, as there is no intent to do harm, but the important questions are practical ones. Assuming that a disabled person will work less, or less efficiently, than others, who will compensate the employer? Assuming this same person still needs to eat, who will provide the worker with compensations for their lost wages? Is it more economical to allow disabled people to stay at home, presumably supported by family, or would it be more efficient to organize government or for-profit facilities to house them? 
There are several unanswerable questions to ask before we would know how an economic model of first contact would affect humanity. What kind of economy could be at play among or within advanced civilizations? What jobs would there be, and could humans do them? As one of the least technologically advanced civilizations, is there anything we can do that could not be more efficiently done by machines or any service we could provide that could not be provided elsewhere for less trouble? What would happen to us if we refused to work, or if we simply were not needed among beings whose culture was millennia more advanced than our own? Assuming there is a galactic economy, what would become of humankind if we could not participate?

Is this, perhaps, another solution to the Fermi paradox: we have been appraised and found functionally worthless? It is possible that the economic model might motivate interplanetary slave traders who would cross interstellar distances to take the labor they wanted from us without recompense, but again, given the distances and the expense of the journey, this hardly seems profitable-and this is all about profit. It is also difficult to imagine why and how enslaved humans could provide any value that would not more easily be procured through the use of machines.

\section{The Social Model}

No amount of SMILING at a flight of stairs has ever made it turn into a ramp, and no amount of standing in the middle of a bookshelf and radiating your POSITIVE ATTITUDE is ever going to turn all those books into braille. (Young 2012)

Among the more recent models, and the one favored by disabled rights advocates, is the social model of disability. While acknowledging that bodies are different and that people do possess different abilities, this model locates the problem disabled people face not in their bodies or in their failure to believe, act, or work correctly, but in the physical and cultural constructs in which they must live.

Able-bodied people organize their lives and their cultures in ways that are convenient for them. This becomes obvious after just a few moments of reflection: since humans cannot fly, doorways are built near ground level rather than on rooftops. But because most people can walk up flights of stairs, stairs are everywhere. Since we have (as compared with other mammals) an appallingly bad sense of smell, we do not rely on our noses to identify products in the grocery store. Instead, we use pictures and printed words on the packaging to tell us what is inside, effectively replacing input from one sense that does not serve us well with another. Since we cannot shout loudly enough to be heard even throughout a single large building, we have invented loudspeakers and vast, intricate telecommunications systems to carry our voices electronically where we want them to go. None of these things is inherently bad; they have brought us convenience and solved some of our pervasive problems.

They become problematic, however, when it is taken for granted that they are the natural way that things are done and when alternatives are eliminated. The problem of disability in the social model is not the people who cannot climb, see, or hear; it is the built environment that will not compromise in terms of stairs, labels, and telephones. While it is not possible (and some disability activists would argue not desirable) to transform disabled people into able-bodied people, it is quite possible to change the built environment. "Universal design" - a phrase coined by American architect Ronald Mace in the 1980s - is the design of products and environments to be useable by all people, to the greatest extent possible, without the need for adaptations or specialized design, and environments constructed to be usable by disabled people are also generally more usable by everyone.

For example, a well-designed grocery-store parking lot has gently-sloping curb cuts to accommodate wheelchair users-which also accommodate shoppers with carts and parents pushing strollers. Tactile labels and food packaging that is otherwise easy to distinguish by touch would benefit not only blind people but also the sighted person who has to reach onto an overhead shelf or deep into a freezer to retrieve what they want. Announcements made over loudspeakers can also be texted to people's phones, allowing both deaf shoppers and temporarily distracted ones to have access to the information. In these ways, the built environment, which once represented a barrier, becomes a facilitator, and everything is safer and more convenient for everyone. 
Science fiction, along with depictions of various dystopias, has some exceptionally good explorations of universal design on the galactic level. Becky Chambers' Wayfarer series (Chambers 2016), for example, describes public transportation, communication, and even seating at restaurants with thoughtful details pertaining to inclusion and access of many different kinds of species with different physical and sensory needs. Alternate histories (such as Neal Schuster's Fractile Man) describe how environments adapt to suit different kinds of physiology.

We would be fortunate indeed if an ET civilization used something like the social model of disability when interacting with younger civilizations. Since they may well have met dozens or even thousands of such civilizations already, their physical infrastructure and their cultural norms might be quite welcoming and accessible, having stood the test of countless introductions. We might find not only a built environment equally usable by many different species with different ways of getting around and different sensory systems to guide them but also an understanding that sentient species come in a glorious assortment of physical forms-and whatever form you were born with, you are a useful and important member of society.

\section{Conclusions}

Using disability models as a way of examining the first contact with an advanced extraterrestrial civilization provides some new perspectives and possibilities, but it raises more questions than it answers. What, for example, would able-bodied people make of their sudden transformation to second-class status? Would they have the wherewithal and the grace to consult with their disabled neighbors for help? What trends in disability history might inform future investigations? How will this work inform the composition of future space missions? Will it become practical—even necessary—-to include disabled people among early space colonists and explorers? How will living and working in space change our understanding of disability? Are there ways of examining disability that we have not considered here and what might their implications be? In our immediate context, though, perhaps the most pressing question is this: when there is no first-contact event immediately apparent, is any of this relevant or useful? We believe that it is.

Part of the work in the social aspects of astrobiology is in studying ourselves as preparation for welcoming whatever beings we may eventually meet. If this study reveals places where we can do better, then the effort was worthwhile. We can pursue positive changes such as the hopeful and innovative work being done in the theology of disability (Eiesland 1994). The religious/moral models of disability discussed above are, in fact, undergoing something of a renaissance, incorporating the voices of disabled leaders into new ways of integrating the spiritual with the lived experience of disability. We can support the work of disabled activists and storytellers whose work brings us together while it calls for social change (Kleege 1999). And we can continue to work for the political and social change that we know we need. When considering the possibilities of what ET could bring, it becomes imperative to recognize humanity's failings to truly understand what changes could be made to ensure ET reacts positively to us.

This may not change anything about what happens during or after the first contact, but it can change how we live until then.

Author Contributions: Conceptualization, S.W.-J. and A.Z.; methodology, S.W.-J. and A.Z.; software, S.W.-J. and A.Z.; formal analysis, S.W.-J.; writing-original draft preparation, S.W.-J. and A.Z.; writing-review and editing, S.W.-J. and A.Z. All authors have read and agreed to the published version of the manuscript.

Funding: This research received no external funding.

Conflicts of Interest: The authors declare no conflict of interest. 


\section{References}

Ambrosino, Brandon. 2016. If We Make Contact with Aliens, How Would Religions React? BBC Future, December 16. Arthur, W. Brian. 2011. The Nature of Technology: What It Is and How It Evolves. New York: Free Press.

Brown, Lydia. 2011. The Significance of Semantics: Person-First Language: Why It Matters. Boston: Autistic Hoya. Brown, Steven. 2002. What is Disability Culture? Disability Studies Quarterly 22: 34-50. [CrossRef]

Camble, Jane, and Mike Oliver. 1996. Disability Politics: Understanding Our Past, Changing Our Future. Abingdon: Routledge.

Chambers, Becky. 2016. The Long Way to a Small Angry Planet. London: Harper Voyager.

Davies, Paul. 1995. Are We Alone? Philosophical Implication of the Life of Discovery of Extraterrestrial Life. New York: Basic Books.

Davis, Lennard. 2017. Beginning of Disability. Abingdon: Routledge.

Dick, Steven J. 2018. Astrobiology, Discovery, and Societal Impact. Cambridge: Cambridge University Press.

Eiesland, Nancy L. 1994. The Disabled God: Toward a Liberatory Theology of Disability. Abingdon: Abingdon Press.

Evans, Suzanne E. 2004. Forgotten Crimes: The Holocaust and People with Disabilities. Chicago: Ivan R Dee, Inc.

Harari, Yuval Noah. 2015. Sapiens: A Brief History of Humankind. New York: Harper.

Henderson, George, and Willie V. Bryan. 2011. Psychosocial Aspects of Disability. Springfield: Charles C Thomas Pub Ltd.

Kleege, Georgina. 1999. Sight Unseen. London: Yale University Press.

Nielsen, Kim E. 2013. A Disability History of the United States. Boston: Beacon Press.

Niemann, Susan. 2005. Persons with Disabilities. In Religious and Spiritual Issues in Counseling: Applications Across Diverse Populations. Edited by Mary Burke, Jane Chauvin and Judith Miranti. Abingdon: Brunner-Routledge.

Olaore, Israel B., and Augusta Y. Olaore. 2014. Is HIV/AIDS a Consequence or Divine Judgement? Implications for Faith-Based Social Services. A Nigerian Faith-Based University's Study. SAHARA-J: Journal of Social Aspects of HIV/AIDS 11: 20-25. [CrossRef] [PubMed]

Olkin, R. 1999. What Psychotherapists Should Know about Disability. New York: Guilford Press.

Pardeck, Jean A., and John W. Murphy. 2005. Disability Issues for Social Workers and Human Services Professionals in the Twenty-First Century. Abingdon: Routledge.

Petro, Anthony. 2015. After the Wrath of God: AIDS, Sexuality, and American Religion. Oxford: Oxford University Press. Pfeiffer, David, Patrick Devlieger, and Frank Rusch. 2003. Rethinking Disability: The Emergency of New Definitions, Concepts, and Communities. Antwerpen: Garant.

Porter, Roy. 2004. Blood and Guts: A Short History of Medicine. New York: W. W. Norton \& Company.

Retief, Marno, and Rantoa Letsosa. 2018. Models of Disability: A Brief Overview. HTS 74. [CrossRef]

Roberts, Oral. 1966. God's Formula for Success and Prosperity. Highland Heights: Abundant Life Publications.

Rose, Damon. 2019. Stop Trying to Heal Me. BBC, April 27.

Sherry, Mark, Terje Olsen, Janikke Solstad Vedeler, and John Eriksen. 2019. Disability Hate Speech: Social, Cultural, and Political Contexts. Abingdon: Routledge.

Sherry, Mark. 2010. Disability Hate Crimes: Does Anyone Really Hate Disabled People? Abingdon: Routledge.

Shostak, Seth. 2018. Fermi Paradox. Mountain View: SETI Institute.

Ferengi Rules of Acquisition. 1993, In Star Trek: Deep Space Nine, Season 1, Episode 11, "The Nagus". Hollywood: Paramount Domestic Television.

The Thatcher Interview-Jobs, Prices, Taxes. 1981, In Weekend World. London: London Weekend Television.

Thomas, David, and Honor Woods. 2003. Working with People with Learning Disabilities. London: Jessica Kingsley Publishers.

Vaughan, Edwin C. 2009. People First Language: An Unholy Crusade. Ottawa: NFB.

Weintraub, David A. 2014. Religions and Extraterrestrial Life: How Will We Deal with It? Berlin: Springer.

Wells-Jensen, Sheri, and Claire Wells-Jensen. 2019. Very Bad Bedside Manner. In Disability Hate Speech. Edited by Mark Sherry, Terje Olsen, Janikke Solstad Vedeler and John Eriksen. Abingdon: Routledge.

Wilkin, David. 2019. Disability Hate Crime: Experiences of Everyday Hostility on Public Transport. London: Palgrave Pivot.

Wilkinson, Bruce. 2013. The Prayer of Jabez: Breaking Through to the Blessed Life. Escondido: Mission Audio.

Williamson, Bess. 2019. Accessible America: A History of Disability and Design. New York: NYU Press. 
World Health Organization. 1976. International Classification of Impairments, Disabilities, and Handicaps. Geneva: World Health Organization.

Young, Stella. 2012. We're Not Here for your Inspiration. ABC, July 2.

Publisher's Note: MDPI stays neutral with regard to jurisdictional claims in published maps and institutional affiliations.

(C) 2020 by the authors. Licensee MDPI, Basel, Switzerland. This article is an open access article distributed under the terms and conditions of the Creative Commons Attribution (CC BY) license (http://creativecommons.org/licenses/by/4.0/). 